\title{
Developing and validating a nursing strategic plan for COVID-19 pandemic
}

\author{
Magda Atiya Gaber* \\ Faculty of Nursing, Zagazig University, Egypt
}

Received: December 21, 2020

Accepted: March 22, $2021 \quad$ Online Published: March 25, 2021

DOI: $10.5430 /$ jnep.v11n $7 \mathrm{p} 51$

URL: https://doi.org/10.5430/jnep.v11n7p51

\begin{abstract}
Background: Although there were many cautions about a probable pandemic, the health organizations have not prepared to deal with the COVID-19 pandemic. Coronavirus outbreak is a dangerous threat to humanity. An essential concern to control this pandemic is to outline an action plan, set an evaluation frame, identify monitoring techniques, detect measures, and recognize key performance factors and investigations providing evidence-based information.

Methods: The descriptive and methodological design was used to achieve the objectives of the present study. This study was conducted at Zagazig University Hospitals (ZUH's), Egypt. Three types of samples were used: A convenience sample ( $=110)$ including the nursing leaders, a stratified proportionate random sample $(n=302)$ from different categories of nurses, and a Jury committee $(n=9)$. One 1Questionnaire format and 2 opinionnaire sheets were utilized for data collection.

Results: Statistically significant differences were found between nurses and nursing leaders concerning the dimensions of vision ( $p$-value .000), mission ( $p$-value .006), SWOT analysis ( $p$-value .008), goals and objectives ( $p$-value .000), the lines of business ( $p$-value .000), the strategic business units ( $p$-value .000), general strategic items( $p$-value .013), and action plan (role of nursing staff during the epidemic, $p$-value .000; immediate evacuation system, $p$ value .000 ; training, and hospital status during the epidemic, $p$-value .000; availability of the necessary equipment, supplies, and tools to face the epidemic and consumables, $p$-value .000; precautions inside the hospital, $p$-value .010; and infection control, $p$-value .002). However, there was no significant difference between nurses and nursing leaders regarding dimensions of planning for the planning, values, the key performance indicators, and the evaluation of the nursing strategic plan for COVID-19.

Conclusion and recommendations: The questionnaire format of assessing nurses' awareness about the nursing strategic plan for COVID-19 is reliable, valid, and usable. Nurses' awareness about a nursing strategic plan for COVID-19 was generally poor and needs to be raised. The nursing strategic plan for COVID-19 was developed and validated. The suggested strategic plan for COVID-19 should be utilized at ZUH's. ZUH's should allocate the needed and required resources for the application of the recommended plan for overcoming COVID-19 or any future occurrences.
\end{abstract}

Key Words: COVID-19, Pandemic, Nursing, Developing, Validating, Strategic planning

\section{INTRODUCTION}

Coronavirus has appeared as a second highly infectious disease that endangers humans in the 21 st century. ${ }^{[1]}$ Furthermore, humans were exposed to a seriously sudden outbreak starting the era of COVID-19. ${ }^{[2]}$ As well as Bucciardini et al. ${ }^{[3]}$ emphasize that the coronavirus pandemic was not predicted, at least not by decision-makers. Meanwhile the worldwide epidemic of COVID-19, nurses have replied to the call to the carefulness of those infected with coronavirus and to aid inhibit the extra spread of the fatal illness. The construction of clear nursing management guidelines can help nurses provide improved care for patients with COVID-

*Correspondence: Magda Atiya Gaber; Email: dr.magda_gaber@yahoo.com; Address: Faculty of Nursing, Zagazig University, Egypt. 
19 and enhance patient results. Creating and introducing obvious plans before the pandemic and knowing what to do previously causes an irresistible invasion of rigorously ill patients, can eventually offer improved outcomes and also can protect nursing staff. Nursing management for patients with COVID-19 includes assessment, diagnosis, the development of nursing care plans and goals, interventions, evaluations, and documentation. ${ }^{[4]}$

Nursing is a huge organization; Nurses know the nursing process; consider strategic planning as an outstretched and developed form of the nursing process that can be utilized to plans, problems, and practices. Change management in health care deference the culture, work, and field of nursing by implementing strategic planning principles to nursing that are consistent with the knowledge and practice of the nursing profession determining where is nursing now? And providing a vision that leads nursing's upcoming work. ${ }^{[5]}$ Nurses and nursing leaders, especially those driving advanced nursing practice initiatives, should have an understanding of strategy, strategic planning to identify strategies for change. Strategies influence health policy and the consequential healthcare provided to individuals, families, and communities. ${ }^{[6]}$

The research questions were:

1) How to assess nurses' and nursing leaders' awareness about the nursing strategic plan for the COVID-19 pandemic at Zagazig University Hospitals?

2) Are nurses and nursing leaders aware of a nursing strategic plan for the COVID-19 pandemic at Zagazig University Hospitals?

3) What are the components of a nursing strategic plan required for managing the COVID-19 pandemic and any future pandemics?

\subsection{Background}

COVID-19 pandemic showed that health impacting all other aspects of life as well as pushing decision-makers to take significant decisions at the top of the administrative agenda. ${ }^{[7]}$ Moreover, Nacoti et al. ${ }^{[8]}$ said that the health care organizations have not ready to manage the pandemic despite the widespread alerts predicted a potential pandemic. Further, Paneru ${ }^{[9]}$ mentioned that health workers are now working under great stress amongst inadequate health resources such as insufficient staffing.

Nurses have essential obligations, roles, and duties during the COVID-19 epidemic. They will endure being at the front line of patient care in hospitals. Nurses have to confirm that all patients obtain high-quality services regardless of their communicable status. They will also engage in planning for expected COVID-19-related epidemics, which raise the request for nursing services. Moreover, nurses must sustain effective equipping and use of sanitation resources and personal protective equipment and provide inspection data, quarantine instructions, and triage procedures founded on the newest guidance. Worldwide epidemic requirements sturdy nursing staff active participation in management, awareness, and information reciprocity. ${ }^{[10]}$ Nurses are nowadays strongly incorporated in COVID-19 activities, and they will continue the main participant in preventing and controlling the pandemic. So, they must be empowered with a healthy work setting. This setting has to be a judgment-free climate, where they will be allowed to note on incidents as exposure to infection control risks, or reports of mistreating or misuse, and to make quick follow-up act as the provision of counseling. Job-related security is vital to nurses' work throughout COVID-19. ${ }^{[11]}$

As nurses are at the front line of the COVID-19 incidence and facing the risk of infection, they must be protected to save themselves with definite infection preventive measures and adequate providing of protective tools at their worksites, containing masks, gloves, coats, eye cover, face shields, and ventilators. Nursing leaders and instructors must provide instructions, directions, guidance, and support to nurses. ${ }^{[12]}$ Now, there has been considerable misunderstanding around the ways and means of spread of COVID-19. Nurses embrace a crucial role, as one of the most known health care teams, in giving community awareness about illness prevention and in reducing the distribution of myths concerning the epidemic. This includes delivering evidence-based practice, infection-reducing actions, directing individuals to access health services, and dealing with myths. ${ }^{[13]}$ In the same context, throughout epidemics, nurses ought to continuously care for infectious cases, particularly in demanding circumstances with rare or inaccessible resources and uncontrolled infection. Nurses and their workmates will be required to regulate how much care they could provide to others in eras of contagions, at the same time they have to care for themselves. ${ }^{[14]}$

The principal role of nurse leadership will be to warrant that suitable prevention measures and safety are applied to diminish the hazards of the workplace. Nurse leadership has to maintain personal protective equipment (gloves, gowns, masks, soap, disinfectants, and water, and cleaning materials) in sufficient quantities. Nursing superiors should give nurses all required information regarding how to use personal protective equipment, how to deal with infected cases, safety, infection control, and prevention, how to do frequently selfassessments, how to follow quarantine actions. ${ }^{[11]}$ Nursing managers and supervisors should advocate for nurses and emphasize their right to withdraw from a work plan if they have reasonable causes to complete that their duties need a major 
danger to their life or safety. They should protect nurses from any threats. Additionally, if nurses are infected with COVID-19, they should be given the right to receive medical care, counseling, compensation, psychological support. ${ }^{[15]}$

A crucial concern to confront this pandemic is to: outline an action plan, set an appraisal framework, determine a monitoring system, identify definite measures, detect clear pointers and make inspections that giving evidence-based data. ${ }^{[16]}$ Strategic planning is setting a vision for the future. Strategic planning is found to have a positive influence on organizational performance. For executives: they will have the best conception of the goals and objectives they wish to achieve and channels to do that. For staff, the process can stimulate growth in their work rate and output, leading to the fulfillment of the work. All staff should share and participate in the strategic planning process. The nurses who are engaged in day-to-day actions can offer leaders a distinctive outlook of the organization. Nurses can discuss with managers what they think is and isn't working with the work today, which can tell managers planning for the future. ${ }^{[17]}$ The key elements of the strategic planning process are: defining the mission, vision, and major goals of the organization; analyzing the external and internal environments of the organization; choosing the model that will be used in planning methodology and strategies that align an organization's strengths and weaknesses with external environmental opportunities and threats; and adopting organizational structures and control systems to implement the organization's chosen strategies. ${ }^{[18]}$

COVID-19, a novel and poorly understood infectious disease, has no known effective treatment plan. ${ }^{[19]}$ As COVID-19 makes its way around the world, every country must decide when and how to act. Yet many knowledge gaps continue. Little is known about COVID-19 as it is a new communicable disease; therefore, presently, there is no definite treatment available for COVID-19. Responding to the urgent need for dealing with the situation, it is essential to develop effective intervention methods for controlling COVID-19 disease. Since the outbreak starting, many researchers have performed clinical research trials, aiming to develop strategies for the treatment, prevention, and diagnosis of the pandemic. ${ }^{[20]}$ However, to date, developing a nursing strategic plan for COVID-19 is lacking. Therefore, we conducted this paper aimed to meet this need by developing a nursing strategic plan for COVID-19 to reduce, control the spread of the virus and prevent similar pandemics in the future.

\subsection{Significance}

Exposure to pandemics especially COVID-19 changes the priorities in research plans nationally and internationally. As responding to the new instructions from the strategic plan- ning unit at Zagazig University to make adjustments to the strategic plan for every department and faculty to incorporate researches covering the COVID-19 pandemic. Never before, have so many experts in so many countries focused simultaneously on a single topic, COVID-19, and with such urgency and resolve. Nearly all other research has ground to a halt. As well as Because of rapidly changing technology, the environment changes so frequently. Besides, health-care organizations are finding it increasingly difficult to identify long-term needs appropriately and plan accordingly. Most long-term planners today find it difficult to plan more than a few years ahead. So the development of a nursing strategic plan for the COVID-19 pandemic at Zagazig University Hospitals is very important and it is considered to be a key requirement to: overcome pandemic, manage the pandemic's consequences and prevent recurrences of similar pandemics. serve as a guide for any future pandemics, identify how best to respond to opportunities and challenges, lead to more efficient decision making, enhance the communication inside and outside the hospitals, contribute to providing safe, high quality and effective nursing care, promote nursing staff satisfaction, ensure patient satisfaction and provide nurse managers and staff nurses who are autonomous and selfdirected.

\section{Methods}

\subsection{The study aim}

This study aimed to develop and validate a nursing strategic plan for COVID-19 pandemic. The objectives were to develop a tool measuring nursing strategic plan for COVID-19 pandemic, test the validity and reliability of the established tool, assess the nursing strategic plan for COVID-19 pandemic at Zagazig University Hospitals, develop a nursing strategic plan for COVID-19 pandemic based on the assessment data and examine the validity of the designated plan.

\subsection{The study design}

The descriptive and methodological design was used to achieve the objectives of the present study; it aimed at developing and validating nursing strategic plan for the COVID-19 pandemic at Zagazig University Hospitals.

\subsection{Ethical considerations}

Managerial arrangements, official permission was obtained from the chairman of the board of trustees at Zagazig University Hospitals to conduct the study and to collect the data. The researcher explained the aim of the study to participants. Nurses and nursing leaders were fully informed about the research aim and then, agreed to join the research process. All of them voluntarily responded to the questionnaire. The 
research was employed through the principles of the Declaration of Helsinki.

\subsection{Setting}

This study was conducted at Zagazig University Hospitals in Egypt. That includes two sectors involving 8 hospitals with a capacity of approximately 2,168 beds.

\subsection{Sample}

Three types of samples were used: a convenience sample $(\mathrm{n}=110)$ including nursing leaders at Zagazig University Hospitals who agreed to participate in the study completed the survey giving a response rate of $(88.7 \%)$, secondly. a stratified proportionate random sample $(n=302)$ giving a response rate of $91.2 \%$ from different categories of nursing staff. Exclusion criteria include staff nurses less than one year of employment and lastly jury committee $(n=9)$. They were (5) professors and experts in strategic planning (head and members of strategic planning unit at Zagazig University), 1 faculty staff member from faculty of nursing, Zagazig University, and 3 nursing leaders at Zagazig University Hospitals.

\subsection{Instruments}

Data for the present study was collected using the following tools:

\section{a-Questionnaire format}

The questionnaire form was developed by the researcher based on the literature aimed to assess the study sample awareness about a nursing strategic plan for COVID-19 pandemic at Zagazig University Hospitals. It includes two parts; the first part contains socio-demographic data of sample subjects. The second part contained 12 dimensions involving 183 items. The participants were instructed to rate each item using yes/No.

\section{b-Two Opinionnaires}

Two types of sheets were designed to assess the content validity and face validity of the assessment questionnaire form and the developed nursing strategic plan for COVID-19. It involved two parts: a) the opinions of the experts for each item were recorded on a two-point scale: relevant, not relevant, and b) general or overall opinions about the form.

\subsection{Data collection}

The current study was carried out in three phases; firstly, a preparation phase in which the researcher developed the assessment questionnaire tool, tested its content validity, conducted a pilot study, and examined the questionnaire reliability (Split-Half Reliability was .914-.959, Average ItemTotal Correlation was .961 and Cronbach's alpha was .960, secondly, implementation phase, data collection took two months. Filling the questionnaire sheet was ranged from 50 minutes to -1 hour; this time was depending on the work conditions and interference of many variables. Data collection for some participants was carried out through the distribution of the questionnaire sheet to the subjects and was handed back to the researcher upon completion. Thirdly, designing or developmental phase: Based on the results of the assessment and an extensive review of relevant literature, ${ }^{[17,21-26]}$ the researcher created the proposed nursing strategic plan for COVID-19 pandemic and any future pandemics at Zagazig University Hospitals guided by the Pfieffer model $^{[27]}$ of strategic planning then designed an opinionnaire sheet to assess the validity of the suggested strategic plan. Then the final component of the nursing strategic plan was developed.

\subsection{Data analysis}

Data entry was done using Microsoft Excel computer software package, while statistical analysis was done using SPSS version 25.0 statistical software packages. Quality control was done at the stages of coding and data entry. Data were presented using measures of central tendency and dispersions in the form of mean, standard deviation, and independent -samples $t$-test.

\section{RESULTS}

\subsection{Demographic characteristics of the study sample}

According to the results, the mean age of nursing staff in the sample was $33.09 \pm 7.72 \mathrm{SD}$ years and nursing leaders was $36.28 \pm 8.49$ SD. The mean of the years of nurses' experience was $13.17 \pm 8.27 \mathrm{SD}$ years and nursing leaders was $16.40 \pm 7.97 \mathrm{SD}$. The nursing diploma qualification was the highest $(80.5 \%)$, meanwhile, slightly less than onequarter of the sample (19.5\%) were bachelor degree nurses. $73.3 \%$ of the study sample works as a staff nurse, while nursing leaders represented (26.7\%) of job positions. Most of them $(94.0 \%)$ were females.

\subsection{Assess nurses' and nursing leaders' awareness of nursing strategic plan dimensions for COVID-19}

As show in Table 1, the study samples' awareness was very low; there was no significant difference between nurses and nursing leaders regarding all items of planning for the planning of strategic plan preparedness for COVID-19.

Table 2 shows that no significant difference was found between nurses and nursing leaders about the values of the nursing strategic plan for COVID-19. Both of them were not aware of values. 
Table 1. Nurses' and nursing leaders' awareness of planning for planning ( $\mathrm{n}=302$ nursing staff, $\mathrm{n}=110$ nursing leaders)

\begin{tabular}{llllll}
\hline \multirow{2}{*}{ s.n } & $\begin{array}{l}\text { The nursing strategic plan dimensions for } \\
\text { COVID-19 }\end{array}$ & $\begin{array}{l}\text { Nursing staff } \\
\mathbf{n}=\mathbf{3 0 2}\end{array}$ & $\begin{array}{l}\text { Nursing leaders } \\
\mathbf{n}=\mathbf{1 1 0}\end{array}$ & \multirow{2}{*}{-test } & \multirow{2}{*}{ Sig } \\
\hline \multirow{2}{*}{$\mathbf{1 -}$} & \multirow{2}{*}{ Planning for planning } & $\times \% \pm \mathrm{SD}$ & $\times \% \pm \mathrm{SD}$ & -1.036 & .301 \\
\cline { 3 - 5 } & & $1.1188 \pm .23544$ & $1.1455 \pm .21693$ & & \\
\hline
\end{tabular}

Table 2. Nurses' and nursing leaders' awareness of the values of the nursing strategic plan for COVID-19 ( $\mathrm{n}=302$ nursing staff, $\mathrm{n}=110$ nursing leaders)

\begin{tabular}{llllll}
\hline \multirow{2}{*}{ s.n } & $\begin{array}{l}\text { The nursing strategic plan } \\
\text { dimensions for COVID-19 }\end{array}$ & $\begin{array}{l}\text { Nursing staff } \\
\mathbf{n}=\mathbf{3 0 2}\end{array}$ & $\begin{array}{l}\text { Nursing leaders } \\
\mathbf{n}=\mathbf{1 1 0}\end{array}$ & \multirow{2}{*}{-test } & Sig \\
\hline \multirow{2}{*}{$2-$} & Values & $\times \% \pm \mathrm{SD}$ & $\times \% \pm \mathrm{SD}$ & \multirow{2}{*}{-.495} & .621 \\
\cline { 3 - 6 } & & $1.8781 \pm .24722$ & $1.8909 \pm .18100$ & & \\
\hline
\end{tabular}

Table 3 illustrates that a statistically significant difference was found between nurses and nursing leaders concerning the vision of the nursing strategic plan for COVID-19 at a $p$-value (.000). The nursing staff was aware of vision more than nursing leaders.

Table 4 displays that a statistically significant difference was found between nurses and nursing leaders as regards the mis- sion of the nursing strategic plan for COVID-19 at a $p$-value (.006). Nursing leaders were aware of mission more than nurses.

Table 5 clarifies that there was a statistically significant difference at $p$-value (.008) between nurses and nursing leaders regarding the SWOT analysis of the strategic factors. Nursing leaders were aware of SWOT analysis more than nurses.

Table 3. Nurses' and nursing leaders' awareness about the vision of the nursing strategic plan for COVID-19 ( $\mathrm{n}=302$ nursing staff, $\mathrm{n}=110$ nursing leaders)

\begin{tabular}{llllll}
\hline s.n & $\begin{array}{l}\text { The nursing strategic plan } \\
\text { dimensions for COVID-19 }\end{array}$ & $\begin{array}{l}\text { Nursing staff } \\
\mathbf{n}=\mathbf{3 0 2}\end{array}$ & $\begin{array}{l}\text { Nursing leaders } \\
\mathbf{n}=\mathbf{1 1 0}\end{array}$ & $\boldsymbol{t}$-test & Sig \\
\hline \multirow{2}{*}{$3-$} & Vision & $\times \% \pm \mathrm{SD}$ & $\times \% \pm \mathrm{SD}$ & 4.415 & $.000^{*}$ \\
\cline { 3 - 5 } & & $1.9084 \pm .22910$ & $1.7879 \pm .28459$ & \\
\hline
\end{tabular}

${ }^{*} p<.05$

Table 4. Nurses' and nursing leaders' awareness about the mission of the nursing strategic plan for COVID-19 ( $\mathrm{n}=302$ nursing staff, $\mathrm{n}=110$ nursing leaders)

\begin{tabular}{llllll}
\hline s.n & $\begin{array}{l}\text { The nursing strategic plan } \\
\text { dimensions for COVID-19 }\end{array}$ & $\begin{array}{l}\text { Nursing staff } \\
\mathbf{n}=\mathbf{3 0 2}\end{array}$ & $\begin{array}{l}\text { Nursing leaders } \\
\mathbf{n}=\mathbf{1 1 0}\end{array}$ & $\boldsymbol{t}$-test & Sig \\
\hline \multirow{2}{*}{$4-$} & Mission & $\times \% \pm \mathrm{SD}$ & $\times \% \pm \mathrm{SD}$ & -2.303 & $.006^{*}$ \\
\cline { 3 - 4 } & & $1.8642 \pm .34310$ & $1.9455 \pm .22813$ & \\
\hline
\end{tabular}

${ }^{* p}<.05$

Table 5. Nurses' and nursing leaders' awareness about the SWOT analysis of the strategic factors $(\mathrm{n}=302$ nursing staff, $\mathrm{n}$ $=110$ nursing leaders)

\begin{tabular}{llllll}
\hline s.n & $\begin{array}{l}\text { The nursing strategic plan dimensions } \\
\text { for COVID-19 }\end{array}$ & $\begin{array}{l}\text { Nursing staff } \\
\mathbf{n = 3 0 2}\end{array}$ & $\begin{array}{l}\text { Nursing leaders } \\
\mathbf{n}=\mathbf{1 1 0}\end{array}$ & $\boldsymbol{t}$-test & Sig \\
\hline \multirow{2}{*}{$5-$} & $\begin{array}{l}\text { SWOT analysis (Strengths, weaknesses, } \\
\text { opportunities, and threats) }\end{array}$ & $\times \% \pm \mathrm{SD}$ & $\times \% \pm \mathrm{SD}$ & -.149 & $.008^{*}$ \\
\cline { 2 - 4 } & & $1.6149 \pm .13805$ & $1.6170 \pm .07817$ & & \\
\hline
\end{tabular}

$* p<.05$; SWOT (Strengths, Weaknesses, Opportunities, Threats)

As evident from Table 6, a statistically significant difference was found at $p$-value (.000) between nurses and nursing leaders relating to the goals and objectives of the nursing strategic plan for COVID-19 in which nursing leaders were aware of

goals and objectives more than nurses.

Table 7 shows that, there was a statistically significant difference between nurses and nursing leaders regarding the lines of business of the nursing strategic plan for COVID-19 at a 
$p$-value (.000) in which nursing leaders were aware of the lines of business more than nurses.

Table 8 describes that a statistically significant difference was found between nurses and nursing leaders concerning the strategic business units in the nursing strategic plan for COVID-19 at $p$ value (.000) while nurses more aware about the strategic business units than nursing leaders.

Table 6. Nurses' and nursing leaders' awareness of the goals and objectives of the nursing strategic plan for COVID-19 (n $=302$ nursing staff, $\mathrm{n}=110$ nursing leaders)

\begin{tabular}{|c|c|c|c|c|c|}
\hline s.n & $\begin{array}{l}\text { The nursing strategic plan } \\
\text { dimensions for COVID-19 }\end{array}$ & $\begin{array}{l}\text { Nursing staff } \\
n=302\end{array}$ & $\begin{array}{l}\text { Nursing leaders } \\
\mathrm{n}=110\end{array}$ & $t$-test & Sig \\
\hline \multirow{2}{*}{$6-$} & \multirow{2}{*}{ Goals and objectives } & $\times \% \pm \mathrm{SD}$ & $\times \% \pm \mathrm{SD}$ & \multirow{2}{*}{0.47} & \multirow{2}{*}{$.000^{*}$} \\
\hline & & $1.8454 \pm .17281$ & $1.8545 \pm .10716$ & & \\
\hline
\end{tabular}

Table 7. Nurses' and nursing leaders' awareness about the lines of business (LOB's) in the nursing strategic plan for COVID-19 $(\mathrm{n}=302$ nursing staff, $\mathrm{n}=110$ nursing leaders

\begin{tabular}{|c|c|c|c|c|c|}
\hline s.n & $\begin{array}{l}\text { The nursing strategic plan } \\
\text { dimensions for COVID-19 }\end{array}$ & $\begin{array}{l}\text { Nursing staff } \\
\mathrm{n}=302\end{array}$ & $\begin{array}{l}\text { Nursing leaders } \\
\mathrm{n}=110\end{array}$ & $t$-test & Sig \\
\hline \multirow{2}{*}{ 7- } & \multirow{2}{*}{ The lines of business } & $\times \% \pm \mathrm{SD}$ & $\times \% \pm \mathrm{SD}$ & \multirow{2}{*}{-4.095} & \multirow{2}{*}{$.000^{*}$} \\
\hline & & $1.7558 \pm .22731$ & $1.8545 \pm .18356$ & & \\
\hline
\end{tabular}

Table 8. Nurses' and nursing leaders' awareness about the strategic business units in the nursing strategic plan for COVID-19 ( $\mathrm{n}=302$ nursing staff, $\mathrm{n}=110$ nursing leaders

\begin{tabular}{lllll}
\hline \multirow{2}{*}{ s.n } & $\begin{array}{l}\text { The nursing strategic plan } \\
\text { dimensions for COVID-19 }\end{array}$ & $\begin{array}{l}\text { Nursing staff } \\
\mathbf{n}=\mathbf{3 0 2}\end{array}$ & $\begin{array}{l}\text { Nursing leaders } \\
\mathbf{n}=\mathbf{1 1 0}\end{array}$ & \multirow{t}{*}{-test } \\
\hline \multirow{2}{*}{$8-$} & The strategic business units & $\times \% \pm \mathrm{SD}$ & $\times \% \pm \mathrm{SD}$ & 3.881 \\
\cline { 3 - 5 } & & $1.2152 \pm .41167$ & $1.0545 \pm .22813$ & $.000^{*}$ \\
\hline${ }^{*} p<.05$ & & &
\end{tabular}

Table 9 manifested that the highest mean percentage (1.19) Table 10 presented that there was a statistically significant of nurses' awareness about KPI's. While there was no sta- difference between nurses and nursing leaders relating to gentistically significant difference between nurses and nursing eral strategic items of the nursing strategic plan for COVIDleaders about the key performance indicators in the nursing 19 at a $p$-value (.013). Nursing leaders were aware of general strategic plan for COVID-19. Nurses more aware of the key strategic items more than nurses.

performance indicators than nursing leaders.

Table 9. Nurses' and nursing leaders' awareness about the key performance indicators (KPI's) in the nursing strategic plan for COVID-19 ( $\mathrm{n}=302$ nursing staff, $\mathrm{n}=110$ nursing leaders

\begin{tabular}{|c|c|c|c|c|c|}
\hline s.n & $\begin{array}{l}\text { The nursing strategic plan } \\
\text { dimensions for COVID-19 }\end{array}$ & $\begin{array}{l}\text { Nursing staff } \\
\mathrm{n}=302\end{array}$ & $\begin{array}{l}\text { Nursing leaders } \\
\mathrm{n}=110\end{array}$ & $t$-test & Sig \\
\hline \multirow{2}{*}{ 9- } & \multirow{2}{*}{$\begin{array}{l}\text { The key performance indicators } \\
\text { (KPI's) }\end{array}$} & $\times \% \pm \mathrm{SD}$ & $\times \% \pm \mathrm{SD}$ & \multirow{2}{*}{1.450} & \multirow{2}{*}{.122} \\
\hline & & $1.1987 \pm .39967$ & $1.1364 \pm .34474$ & & \\
\hline
\end{tabular}

Table 10. Nurses' and nursing leaders' awareness about general strategic items of the nursing strategic plan for COVID-19 ( $\mathrm{n}=302$ nursing staff, $\mathrm{n}=110$ nursing leaders)

\begin{tabular}{lllll}
\hline \multirow{2}{*}{ S.n } & $\begin{array}{l}\text { The nursing strategic plan dimensions } \\
\text { for COVID-19 }\end{array}$ & $\begin{array}{l}\text { Nursing staff } \\
\mathbf{n}=\mathbf{3 0 2}\end{array}$ & $\begin{array}{l}\text { Nursing leaders } \\
\mathbf{n}=\mathbf{1 1 0}\end{array}$ & S-test \\
\hline \multirow{2}{*}{$10-$} & General strategic items & $\times \% \pm \mathrm{SD}$ & $\times \% \pm \mathrm{SD}$ & -2.058 \\
\cline { 3 - 5 }
\end{tabular}


Table 11 revealed that there were statistically significant differences between nurses and nursing leaders regarding action plan categories of the role of nursing staff during the epidemic, immediate evacuation system, training, and hospital status during the epidemic, availability of the necessary equipment, supplies, and tools to face the epidemic and consumables, precautions inside the hospital and infection control at $p$-value $(.000, .000, .000, .000, .010, .002)$ respectively. Nursing leaders were aware of administrative items, the role of nursing staff during the epidemic, immediate evacuation system, training, and hospital status during the epidemic, Availability of the necessary equipment, supplies, and tools to face the epidemic, and consumables more than nurses. While nurses were aware of precautions inside the hospital and infection control than nursing leaders.

Table 12 shows that there was no significant difference between nurses and nursing leaders regarding the evaluation of the nursing strategic plan for COVID-19.

Table 11. Nurses' and nursing leaders' awareness of action plan categories in the nursing strategic plan for COVID-19 ( $\mathrm{n}=$ 302 nursing staff, $n=110$ nursing leaders)

\begin{tabular}{|c|c|c|c|c|c|}
\hline \multirow[t]{2}{*}{ S.n } & \multirow{2}{*}{$\begin{array}{l}\text { The nursing strategic plan dimensions for } \\
\text { COVID-19 }\end{array}$} & $\begin{array}{l}\text { Nursing staff } \\
\mathrm{n}=302\end{array}$ & $\begin{array}{l}\text { Nursing leaders } \\
\mathrm{n}=110\end{array}$ & \multirow[t]{2}{*}{ t-test } & \multirow[t]{2}{*}{ Sig } \\
\hline & & $\times \% \pm \mathrm{SD}$ & $\times \% \pm \mathrm{SD}$ & & \\
\hline \multirow{7}{*}{$11-$} & Administrative items & $1.3336 \pm .23909$ & $1.5325 \pm .24942$ & -7.381 & $.000 *$ \\
\hline & The role of nursing staff during the epidemic & $1.4361 \pm .21788$ & $1.6156 \pm .19993$ & -7.556 & $.000 *$ \\
\hline & Immediate evacuation system & $1.6694 \pm .27153$ & $1.7076 \pm .23482$ & -1.306 & .164 \\
\hline & Training and hospital status during the epidemic & $1.0522 \pm .14965$ & $1.1750 \pm .25466$ & -6.011 & $.000 *$ \\
\hline & $\begin{array}{l}\text { Availability of the necessary equipment, supplies, } \\
\text { and tools to face the epidemic and consumables }\end{array}$ & $1.3825 \pm .25030$ & $1.5409 \pm .21823$ & -5.875 & $.000 *$ \\
\hline & Precautions inside the hospital & $1.6914 \pm .24147$ & $1.6190 \pm .25062$ & 2.666 & $.010^{*}$ \\
\hline & Infection control & $1.5063 \pm .21437$ & $1.4415 \pm .17532$ & 2.844 & $.002 *$ \\
\hline
\end{tabular}

*p<.05

Table 12. Nurses' and nursing leaders' awareness of the evaluation of a nursing strategic plan for COVID-19 ( $\mathrm{n}=302$ staff nurses, 110 nurse leaders)

\begin{tabular}{|c|c|c|c|c|c|}
\hline s.n & $\begin{array}{l}\text { The nursing strategic plan } \\
\text { dimensions for COVID-19 }\end{array}$ & $\begin{array}{l}\text { Nursing staff } \\
\mathrm{n}=302\end{array}$ & $\begin{array}{l}\text { Nursing leaders } \\
\mathrm{n}=110\end{array}$ & $t$-test & Sig \\
\hline \multirow{2}{*}{$12-$} & \multirow{2}{*}{$\begin{array}{l}\text { The evaluation items of a nursing } \\
\text { strategic plan for COVID-19 }\end{array}$} & $\times \% \pm \mathrm{SD}$ & $\times \% \pm \mathrm{SD}$ & \multirow{2}{*}{-.180} & \multirow{2}{*}{.858} \\
\hline & & $1.0513 \pm .16256$ & $1.0545 \pm .15659$ & & \\
\hline
\end{tabular}

\section{DisCuSSIONS}

Currently, the COVID-19 epidemic has not only clarified exactly how "health" is influencing all other aspects of individuals and reciprocally, but it is also pushing policymakers to make vital decisions. ${ }^{[28]}$ Providing safe and quality care in pandemic depends on the health and mental wellbeing of frontline healthcare workers. Health care providers are exposed to extreme tiredness, difficult triage decisions, and segregation from families, stigma, and the sadness for the death of patients and workmates, in addition to their threats of infection. ${ }^{[29]}$

The present results indicated that the study samples' awareness was very low, most nurses and nursing leaders were not aware of the items of (planning for planning) strategic plan preparedness for COVID-19. That might be due to: the pandemic was not predicted, nurses had not prepared to deal with the COVID-19 outbreak, the culture of the hospital

Published by Sciedu Press did not support a planning process, and strategic planning is a challenge to nurses and a very difficult task. This was consistent with Mutafa ${ }^{[30]}$ who found that general knowledge and awareness of nurses about planning was very low with a difference among them, in this context Paterlini ${ }^{[31]}$ mentioned that the health organizations were unready to deal with a pandemic. Also Ebner ${ }^{[32]}$ emphasized that planning to plan is a very important preliminary step in which the institution has to be prepared and committed to engaging in a planning process. Thus Qian et al. ${ }^{[33]}$ recommended that leaders have to take strategic actions immediately to combat the COVID-19. In the same line, Brydges et al. ${ }^{[34]}$ suggested that for responding to COVID-19 outbreaks we have to reorganize our priorities, plan for patient care and systems, and use simulations. Staffs have to depend on numerous technologies to respond to this disaster. Various groups have to created means, like simulated cases and tabletop simula- 
tions, to help frontline healthcare professionals (HCPs) and trainees address knowledge gaps in practice.

According to the present study, it was found that most nurses and nursing leaders were not aware of the values of the nursing strategic plan for COVID-19. According to Qian et al., ${ }^{[33]}$ nurses' awareness of occupational values and how those values influence their performances is a fundamental aspect of nursing care and Hill and Jones ${ }^{[18]}$ confirmed that values are generally seen as the foundation of organizational culture that controls how employees work to achieve an organization's mission and goals. So, Ebola Gbalo Research Group ${ }^{[35]}$ suggested that WhatsApp groups among healthcare staff could be used to circulate messages and information could be shared among employees.

The present study findings referred that there was a statistically significant difference between nurses and nursing leaders concerning the vision in which nursing staff was aware of vision more than nursing leaders that might be due to quality culture and posters of hospital vision but generally nurses and nursing leaders were not aware of how to create a vision which is a hard mission. According to Sullivan, ${ }^{[17]}$ a strategic plan should contain the institution's vision statement and Marquis and Huston ${ }^{[21]}$ added that vision statements are used to define future goals or aims of an organization. It is recommended that workshops should be conducted to train nurses and their leaders about how to create a vision.

The findings of the current study revealed that there was a statistically significant difference between nurses and nursing leaders as regards the mission in which nurse leaders aware of the mission more than nurses. That might be due to general knowledge, quality culture, posters of hospital mission but both of them were not aware of how to craft a mission which is complicated work. Thus it is suggested that training sessions have to be conducted on how to construct missions. This was agreed with Sullivan ${ }^{[17]}$ who mentioned that a strategic plan should contain the mission as well as Ebner ${ }^{[32]}$ who wrote that the development of the shared future state for the organization leads to crafting a mission statement.

The current study results related to SWOT analysis proved that there was a statistically significant difference between nurses and nursing leaders regarding the SWOT analysis of the strategic factors. Nursing leaders were aware of SWOT analysis more than nurses. That could be due to general knowledge, administrative meetings, and quality culture, and accreditation requirements. This result was consistent with Brydges et al. ${ }^{[34]}$ who said that different analytical instruments, ways, and methods are used in strategic planning. These instruments include SWOT analysis, which investi- gates internal strengths and weaknesses as well as external opportunities and threats. In the same line, Sullivan ${ }^{[17]}$ stated that a strategic plan may focus more on the internal and external factors that can pose any threats or challenges to the organization. It was recommended that workshops and training sessions about SWOT analysis should be conducted to nurses and nursing leaders.

The present study results evident that there was a statistically significant difference between nurses and nursing leaders relating to the goals and objectives in which nursing leaders were aware of goals and objectives more than nurses that might be due to educational level and administrative experiences. This was consistent with Ebner ${ }^{[32]}$ who explained that the description of goals is one of the major aspects of formal planning. They should be written, be challenging, and focus on the final objectives for the organization. These ultimate objectives should then be translated into precise measurable objectives. It was recommended that workshops about nursing goals and objectives should be conducted for nurses and nursing leaders.

According to the present study, it was clarified that there was a statistically significant difference between nurses and nursing leaders regarding the lines of business of the nursing strategic plan for COVID-19, in which nursing leaders aware of the lines of business more than nurses. This was agreed with Sullivan ${ }^{[17]}$ who confirmed that a strategic plan should state the lines of business. The findings of the current study exhibited that the highest percentage of nurses and nursing leaders were not aware of the key performance indicators (KPI's) which might be due to nurses and nursing leaders were not trained appropriately to know the KPI's. Thus Maleka ${ }^{[36]}$ confirmed that the strategic plan should specify the critical success factors.

Concerning action plan, there were statistically significant differences between nurses and nursing leaders regarding action plan categories of the role of nursing staff during the epidemic, immediate evacuation system, training, and hospital status during the epidemic, availability of the necessary equipment, supplies, and tools to face the epidemic and consumables, precautions inside the hospital and infection control. Regarding the role of nursing staff during the epidemic, it was noticed that most nurses and nursing leaders were not use nursing informatics, telenursing, modern technology, and telecommunications. That might be due to the high cost of using recent technology, infrastructural limitations as an unstable power supply or limited internet connectivity, and a lack of interoperability between digital systems and there was no training program about telenursing. These findings were not consistent with many researchers as follows: Cher- 
sich et al. ${ }^{[37]}$ clarified that telecommunications technology justifies human resources and lessens patient interface and thus infection dangers. Notably, healthcare workers, using their authoritative voice, can aid effective COVID-19 policies and prioritization of their safety. In the same line Ran et al. ${ }^{[38]}$ recommended that basically, digitalized or telecommunications services could decrease patient dealings and consequently risks for infection, and allow experts to offer counsel and assist less-skillful ones. In the same context, Brazil et al. ${ }^{[39]}$ suggested that WhatsApp groups among healthcare staff could afford instruction on clinical decision making, also be used to circulate messages, new information could be shared among employees.

Relating to the immediate evacuation system, nursing leaders were aware that there is an official responsible for the evacuation system. Also, nurses were aware of the presence of special doors and exits for immediate evacuation that might be due to there were posters and pasted signals for doors but the evacuation was not carried out. This was consistent with Mutafa ${ }^{[30]}$ who indicated that nurses were aware of the transfer of patients to the nearest hospital and calling police or ambulance, oppositely none of them was aware of the fact that exits were always obstructed by stuff.

Concerning training items, nursing leaders were not aware that there was the training conducted hypothetical experiments before the outbreak of the epidemic. However, nurses were not trained to deal with Corona patients. On the other hand, nurses and nursing leaders were not aware that there was a test should be done after training that might be due to there was not proactive approach for training and preparation for future crisis or disasters. This was consistent with $\mathrm{Mu}-$ $\operatorname{tafa}^{[30]}$ who clarified that nurses were aware of the absence of training programs and lack of tests. Thus IANS ${ }^{[40]}$ recommended that using simulation for COVID-19 pandemic preparation has illuminated the role of simulation in health care organizations. The simulation considers an opportunity and an integral element of healthcare provision.

About hospital status during the epidemic, the highest percentage of nurses and nursing leaders were reported that the number of beds was not sufficient to face the epidemic. But nursing leaders were aware that the infected people were sorted and classified in a triage place designated for the reception that might be due to limited financial resources, inadequate government support, and high cost for increasing equipped beds and capacity of hospitals. This was consistent with IANS and Health Emergency Operation Center ${ }^{[40,41]}$ who noted that health staffs are now working under great pressure amongst inadequate health resources such as deficient staffing, isolation beds, and ventilators. So, Khanal et al. ${ }^{[42]}$ suggested that there should be an empowering work environment with a good support system, sufficient accessibility of PPE, appropriate training of health workers on dealing with COVID-19, and focus on incentives that enhance their work morale. Besides Mahase ${ }^{[26]}$ pointed out that the use of personal protective equipment (PPE) containing a gown, gloves, face mask, and a face shield or goggles.

With regard to the hospital have the necessary equipment, supplies, and tools to face the epidemic, the majority of nurses aware that patients' gowns were the most types that were available in the working state and they confirmed the accessibility of linens. Whereas nursing leaders assured the accessibility of thermometers and intravenous devices that might be due to they did not notice shortage relating to these items. This was consistent with Mutafa ${ }^{[30]}$ who observed that bedsheets, covers, and thermometers were the most available types while there were shortages in the sphygmomanometers in different sizes and blankets.

About infection control items, most of the nurses were not aware of undertaken a training program for COVID-19 infection controls, as well as, they were aware that there were isolation departments, and cases were not referred to other hospitals Also, nurses and nursing leaders were aware of the availability of containers for waste in the hospital. However, the majority of nursing leaders were aware of utilizing nonsterile clothes and personnel protective equipment because sterile was not available in the hospital that might be due to no training program undertaken for COVID-19 infection controls, a severe shortage of sterile clothes and personnel protective equipment. This was antagonized with Mutafa ${ }^{[30]}$ who identified that nurses were aware of infection control programs, although it does not include nurses. But was consistent with $\mathrm{Sah}^{[23]}$ who indicated that there were inadequate testing kits and a lack of PPEs. Therefore, Qian et al. ${ }^{[33]}$ recommended that enough facilities have to be available for use in hospitals, such as test kits, facemasks, and PPEs, to prepare the quarantine measures in each gate of the traveling venues, and to prepare information communication, etc. Correspondingly Zhang et al. ${ }^{[2]}$ find that the isolation rooms, the facemasks, and intensified hand hygiene are critical for preventing nosocomial transmission of pandemic respiratory diseases.

Finally, according to the current study, it was illustrated that the study samples awareness were very low, most of the nurses and nursing leaders were not aware that the plan needs to be evaluated, corrected, and re-examined while nurses and nursing leaders were not aware that the performance standards have to defined that might be due to they were not knowledgeable about the evaluation process. Thus 
Sullivan ${ }^{[17]}$ suggested that the strategic plan should address exactly how regularly it will be revised, renews, and updated. To conclude it is recommended that the strategic planning unit in Zagazig University has to organize training programs for nurses and nursing leaders concerning means, process, techniques, etc of strategic planning, finally intervention researches about training programs should be conducted to raise nurses and nursing leaders' awareness about the strategic plan for COVID-19.

\section{CONCLUSION, RECOMMENDATIONS, AND FURTHER STUDIES}

In the light of the present study, the questionnaire format of assessing nurses' awareness of a nursing strategic plan for COVID-19 is reliable, valid, and usable. Based upon the findings of the study, nurses' awareness about the nursing strategic plan for COVID-19 was generally poor and needs to be raised. The nursing strategic plan for COVID-19 was developed and validated. The researcher recommended that the suggested strategic plan for COVID-19 should be utilized at Zagazig University Hospitals; disseminated by ZUH's administration to all nursing staff and leaders; reviewed, revised, and updated annually as appropriate and as necessary to reflect continuing improvements; ZUH's should determine and allocate the needed and required resources for the application of the recommended plan for overcoming COVID-19 or any future occurrences; design and implement training programs for all nursing staff about controlling COVID-19 or any future occurrences; provide rewards to motivate nursing staff for an obligation of universal precautions; Pandemic drills including all nursing staff should be done regularly, and nurses should be included and effectively sharing in the infection control committee. Further researches using the developed tool in other settings

\subsection{Implications}

For nursing practice: Nursing leaders and staff nurses can use this strategic plan which includes an action plan including all activities required for how to deal and overcome the COVID19 pandemic, as well as this plan will help them in any future pandemic, facilitate the work of Nursing leaders in decision - making process during the pandemic, protect the nursing staff, improving nurses' performance, and consequently will positively and effectively reflect on all nursing care rendered. For nursing education: Applying the developed strategic plan as a reference containing the bulk of knowledge added to the nursing knowledge. For nursing research: Replicate the study using the developed tools and the strategic plan in the form of a tool at other sites.

\subsection{Limitations}

The study had some natural limitations. As the study samples were restricted to ZUH's, which may have affected the generalizability of results to other healthcare organizations and the whole country, so there is a necessity for future repetition and expansion of this study to further work contexts having large samples. Besides, the study was dependent on self-reports by the participants utilizing a cross-sectional study design, usual way bias may have happened; therefore, other methods of assessment should be used to get objective data and an intervention study design is required in upcoming studies. The researcher did not find assessment tools appropriate for measuring nurses' awareness about the nursing strategic plan for COVID-19 so further research to develop studies for creating different tools in this area. This study is a vital step towards incorporating strategic planning in nursing especially during epidemics of ZUH's in Egypt as no previous study has been conducted on a similar area in Egypt.

\section{ACKNOWLEDGEMENTS}

The author wishes to thank all of the staff nurses and nursing leaders for their cooperation and everyone had been participate in the conduction of this study.

\section{CONFlicts of InTEREST Disclosure}

The author declares that there is no conflict of interest statement.

\section{REFERENCES}

[1] Zumla A, Alagaili NA, Cotton M, et al. Infectious diseases epidemic threats and mass gatherings: refocusing global attention on the continuing spread of the Middle East Respiratory Syndrome coronavirus (MERS-CoV). BMC Medicine. 2016.

[2] Editorial. Redefining vulnerability in the era of COVID-19. The Lancet. J. 2020; 395(10230): 1089. https ://doi.org/10.1016/ S0140-6736 (20) 30757-1

[3] Bucciardini R, Control B, De Castro P, et al. The health equity in all policies (HEiAP) approach before and beyond the Covid-19 pan- demic in the Italian context. International Journal for Equity in Health. 2020; 19: 92. PMid:32513189 https ://doi.org/10.1186/s129 39-020-01209-0

[4] Hetzler L. Nursing Management of COVID-19. Every nurse. organization. 2020. Available from: https://everynurse.org/blog/ nursing-management-covid-19/

[5] Sare M, Ogilvie L. Strategic planning for nurses: change management in health care Jones and Bartlett Publishers, LLC. London. 2020.

[6] Schober M. Strategic Planning for Advanced Nursing Practice. 
Springer International Publishing AG. Switzerland. 2017. https: //doi.org/10.1007/978-3-319-48526-3_2

[7] Wang Z, Tang K. Combating COVID-19: health equity matters. Nat Med. 2020; 26: 458-64. PMid:32284617 https ://doi .org/10.1 038/s41591-020-0823-6

[8] Nacoti M, Ciocca A, Giupponi A, et al. At the epicenter of the Covid19 pandemic and humanitarian crises in Italy: changing perspectives on preparation and mitigation. NEJM Catalyst Innov Care Delivery. 2020. https://doi.org/10.1056/CAT.20.0080

[9] Paneru HR. Intensive care units in the context of COVID-19 in Nepal: current status and need of the hour. J Soc Anesthesiol Nepal. 2020; 7(1): e291.

[10] Jackson D, Bradbury-Jones C, Baptiste D, et al. Life in the pandemic: some reflections on nursing in the context of COVID19. J Clin Nurs. 2020; 29: 2041-2043. PMid:32281185 https: //doi.org/10.1111/jocn. 15257

[11] Chen X, Tian J, Li G, et al. Initiation of a new infection control system for the COVID-19 outbreak. Lancet Infect Dis. 2020; 20: 397-398. https://doi.org/10.1016/S1473-3099(20) 30110-9

[12] Adams J, Walls R. Supporting the health care workforce during the COVID-19 global epidemic. JAMA. 2020; 323: 1439. PMid:32163102 https://doi.org/10.1001/jama.2020.3972

[13] World Health Organization. Novel Coronavirus (COVID-19). Geneva, Switzerland: World Health Organization; 2020. Available from: https://www. who.int/emergencies/diseases/novel -coronavirus-2019

[14] American Nurses Association. Nurses, Ethics and the Response to the COVID-19 Pandemic. Silver Spring, MD: American Nurses Association; 2020. Available from: https://www.nursingworld.o $\mathrm{rg} /$ coronavirus

[15] Fawaz M, Anshasi H, Samaha A. Nurses at the Front Line of COVID19: Roles, Responsibilities, Risks, and Rights. Am J Trop Med Hyg. 2020; 103(4): 1341-1342. PMid:32783796 https://doi .org/10 .4269 /ajtmh. 20-0650

[16] Bucciardini R, Ferrelli RM, Giammarioli AM, et al. Health inequalities: a research positioning exercise at the National Institute of Health, Italy. EJPH. 2019; 29(5): 943-947. PMid:31219550 https://doi.org/10.1093/eurpub/ckz115

[17] Sullivan H. What Is Strategic Planning? Small Biz Ahead information site, The Hartford. 2020. Available from: https://sba.thehartford.com/business-managemen t/what-is-strategic-planning/

[18] Hill CH, Jones G. Strategic Management: An Integrated Approach, Tenth Edition. The USA. 2013.

[19] Wu JT, Leung K, Leung GM. Now casting and forecasting the potential domestic and international spread of the 2019-nCoV outbreak originating in Wuhan, China: a modeling study. Lancet. 2020.

[20] Zhu RF, Gao Y, Robert S, et al. Systematic review of the registered clinical trials for coronavirus disease 2019 (COVID-19). J Transl Med. 2020; 18: 274. PMid:32631442 https ://doi .org/10.118 6/s12967-020-02442-5

[21] Marquis B, Huston J. Leadership roles and management functions in nursing: theory and application. 8th ed. Wolters Kluwer HealthlLippincott Williams \& Wilkins. New York: 2015.

[22] Chen SH, Nasongkhla J, Donaldson A. Developing Open Educational Resources. International Journal of Information and Education Technology. 2018; 2018; 8(5): 362-368. https://doi .org/10.1 8178/ijiet.2018.8.5.1064

[23] Sah DN. Health workers in Province 1 demand facilities at hospitals to treat Covid-19 patients. The Kathmandu Post. 2020.
[24] Zhang G, Pan H, Hu X, et al. The role of isolation rooms, facemasks, and intensified hand hygiene in the prevention of nosocomial COVID-19 transmission in a pulmonary clinical setting. Infectious Diseases of Poverty. 2020; 9: 104. PMid:32703281 https://doi.org/10.1186/s40249-020-00725-z

[25] Mahase E. Covid-19: retired doctors could be asked to return to work, says Hancock. BMJ (Clinical research ed). 2020; 368: m831. PMid:32122881 https://doi.org/10.1136/bmj .m831

[26] Mahase E. Covid-19: hoarding and misuse of protective gear is jeopardizing the response, WHO warns. BMJ (Clinical research ed). 2020; 368: m869. PMid:32132096 https://doi.org/10.1136/ bmj. $\mathrm{m} 869$

[27] Pfeffer J. Applied strategic planning. Marshfield: Pitman Publishing, Inc. 1992.

[28] World Health Organization. Governance for health equity taking forward the equity values and goals of health 2020 in the WHO European region. Copenhagen. 2014. Available from: http://www. euro.w ho.int/data/assets/pdf_file/0020/235712/e96954.pdf

[29] Regly E. Italian doctors' fatalities reach tragic levels as they fight COVID-19 in overburdened hospitals. The Globe and Mail. 2020. Available from: https://www. Theglobeandmail.com/world/ article-italian-doctors-fatalities-reach-tragiclev els-as-they-fight-covid-1/

[30] Mutafa G. developing a nursing disaster plan for the emergency hospital at Mansoura University. Unpublished doctorate thesis. Faculty of Nursing, Ain shams University, Egypt. 2003.

[31] Paterlini M. Italy's health system reforms on hold. Lancet. 2013; 381(9872): 1085-6. https://doi.org/10.1016/S0140-673 6 (13) $60745-\mathrm{X}$

[32] Ebner D. Formal and Informal Strategic Planning. Springer Gabler Austria. 2014.

[33] Qian X, Ren R, Wang Y, et al. Fighting against the common enemy of COVID-19: a practice of building a community with a shared future for mankind. Infectious Diseases of Poverty. 2020; 9: 34 PMid:32264957 https://doi.org/10.1186/s40249-020-006 50-1

[34] Brydges R, Campbell D, Beavers L, et al. Lessons learned in preparing for and responding to the early stages of the COVID19 pandemic: one simulation's program experience adapting to the new normal. Advances in Simulation. 2020. PMid:32514385 https://doi.org/10.1186/s41077-020-00128-y

[35] Ebola Gbalo Research Group. Responding to the Ebola virus disease outbreak in DR Congo: when will we learn from Sierra Leone? Lancet. 2019; 393(10191): 2647-2650. https ://doi.org/10.1 016/S0140-6736 (19) 31211-5

[36] Maleka S. Strategic Management and Strategic Planning Process. 2015. Available from: https://www.researchgate.net/publi cation/273757341

[37] Chersich M, Gray G, Fairlie L, et al. COVID-19 in Africa: care and protection for frontline healthcare workers. Globalization and Health. 2020; 16: 46. PMid:32414379 https://doi.org/10.1186/s129 92-020-00574-3

[38] Ran L, Chen X, Wang Y, et al. Risk Factors of Healthcare Workers with Corona Virus Disease 2019: A Retrospective Cohort Study in a Designated Hospital of Wuhan in China Clinical infectious diseases: an official publication of the Infectious Diseases Society of America. Clin Infect Dis. 2020; 71(16): 2218-2221. PMid:32179890 https://doi.org/10.1093/cid/ciaa287

[39] Brazil V, Lowe B, Ryan L, et al. Translational simulation for rapid transformation of health services, using the example of the COVID19 pandemic preparation. Advances in Simulation. 2020; 5: 9. 
PMid:32514386 https://doi.org/10.1186/s41077-020-001 $27-z$

[40] IANS (Indo-Asian News Service). Nepal faces a shortage of vital medical supplies. 2020. Available from: https://www . outlookindia.com/newsscroll/nepal-f aces-shortage-of-vital-medicalsupplies/1853189
[41] Health Emergency Operation Center. Health sector response to COVID-19. 2020. Available from: https://heoc.mohp.gov.np /update-on-novel-corona-virus-covid-19/

[42] Khanal P, Devkota N, Dahal M, et al. Mental health impacts among health workers during COVID-19 in a low resource setting: a crosssectional survey from Nepal. Globalization and Health. J. 2020. 